\title{
Impact of Techno-economic Context on the Continuity of Supply of the European Distribution Networks
}

\author{
N. Pereira ${ }^{1}$, S. Faias ${ }^{1,2,3}$ and J. Esteves ${ }^{1,2}$ \\ ${ }^{1}$ Lisbon Engineering Superior Institute (ISEL) \\ Rua Conselheiro Emídio Navarro, 1, 1950-062 Lisboa (Portugal) \\ 2 Entidade Reguladora dos Serviços Energéticos (ERSE) \\ Rua Dom Cristóvão da Gama, 1 - 3º, 1400 - 113 Lisboa (Portugal) \\ Phone number:+351 213033 200, e-mail: SFaias@erse.pt, JEsteves@erse.pt \\ ${ }^{3}$ INESC ID \\ Rua Alves Redol, 9, 1000-029 Lisboa (Portugal)
}

\section{Key words}

Continuity of supply, electricity distribution, benchmarking, quality of service, economic regulation.

\section{Introduction}

The liberalization of the electricity sector establishes the separation of basic functions of electricity generation, transmission, distribution and supply (or retailing). However, while in the generation and supply functions a potential for competition exists, in the transmission and distribution networks, their natural monopoly nature requires regulation to induce optimal price and quality of service [1]-[3].

The quality of service regulation, with its three dimensions, continuity of supply (network reliability and availability), voltage quality (characteristics of the supply voltage) and commercial quality (timeliness in dealing with customers' requests) provides a balance between customers' willingness to pay network tariffs and their expectations on minimum levels of quality of service. This topic became more relevant with the evolution from a rateof-return economic regulation, in which total utility costs were fully recouped by the tariff, to a price-cap regulation, wherein, with the objective of improving the utilities' economic efficiency, their allowed revenues are capped in a level that does not necessarily reflect the actual costs, leading firms to avoid investments and consequently to decrease the quality of service provided to customers [2], [4]-[6].

This regulation, namely in what concerns continuity of supply dimension, can be exercised with recourse to a set of direct and indirect instruments such as the definition of minimum standards for the continuity of supply indicators and respective individual monetary compensations, financial incentive schemes, regular reporting of continuity of supply indicators and national and international benchmarking [2], [3], [6], [7].

Benchmarking the continuity of supply performance at a national or international level is a very powerful instrument because it introduces competition between utilities and countries. However, this benchmarking should not consider the output performance (continuity of supply indicators) without taking into account some inputs such as the technical characteristics of the network or the economic regulatory context of each country [8], [9]. In this regard, this paper presents an analysis of the European distribution network performance in what concerns continuity of supply. This comparison takes into account the technical characteristics of the networks and the respective regulatory context, with the objective of identifying correlations and isolating some of the characteristics that mainly influence that continuity of supply performance.

For this study, data from the European benchmarking reports published by Council of European Energy Regulators (CEER) is used. More specifically, the preliminary answers to the questionnaire developed for the $6^{\text {th }}$ edition of the CEER Benchmarking on the Quality of Supply. The number of countries considered in the study is 31 , all of them, members or observers of the CEER [10].

The paper, besides the introduction, includes a description of the regulatory context of the countries considered in the study, a technical characterization of their networks, a study on the correlation between continuity of supply performance and techno-economic context and, finally, the conclusions. 


\section{Regulatory Context}

Some characteristics of the regulatory context of a country can influence the continuity of supply performance of its networks. Some of such characteristics are established with the objective of having a direct influence on the network performance, as for instance incentive mechanisms for the improvement of the continuity of supply or standards for individual continuity of supply indicators with financial penalties associated, while some others, such as the levels of CAPEX and OPEX, can have an indirect influence on the network performance.

A characterization of the regulatory context of the different European countries, based on the answers to the questionnaire, is presented in Table I.

According to answers to the questionnaire, in most countries, the regulation on quality of supply is a responsibility of the national regulatory authorities (NRA). However, there are some cases wherein also the government is directly or indirectly involved in the regulation of the quality of supply throughout the ministry and, in other cases, this responsibility is shared with the network operators. In a few countries this responsibility is exclusively from the ministry or from network operators.
Since the data usually used to characterize the quality of supply performance is provided by the operators of the different networks, half of the countries refer that their regulation codes include the possibility of carrying out audits or other kind of controls to the reliability of the data provided and to the information technology that produces the data.

In what concerns the characterization of the continuity of supply performance, half of the countries refer that they have in place indicators to characterize the continuity of supply experienced by individual customers with standards associated. For the most of those countries, monetary compensations are paid to customers in case of not compliance with such individual standards.

Moreover, about half of the responding countries also refer that they have standards associated the overall indicators used to characterize the continuity of supply in their networks. Besides that, more than half of countries have implemented incentive schemes, based on reward or penalties for network operators, with the objective of improving the overall continuity of supply of the respective networks.

Table I. - Regulatory context of the different European countries

\begin{tabular}{|c|c|c|c|c|c|c|c|}
\hline \multirow[t]{2}{*}{ Country } & \multirow[t]{2}{*}{$\begin{array}{l}\text { Responsibility for } \\
\text { regulations/standards }\end{array}$} & \multicolumn{2}{|c|}{$\begin{array}{l}\text { Individual continuity of } \\
\text { supply }\end{array}$} & \multicolumn{3}{|c|}{$\begin{array}{l}\text { Overall continuity of supply } \\
\text { Reward or penalty incentive }\end{array}$} & \multirow{2}{*}{$\begin{array}{c}\text { Audits/controls to } \\
\text { data provided by } \\
\text { operators }\end{array}$} \\
\hline & & $\begin{array}{c}\text { Guaranteed } \\
\text { standards }\end{array}$ & $\begin{array}{c}\text { Monetary } \\
\text { compensations }\end{array}$ & standards & In force & Since & \\
\hline C 1 & NRA & No & No & Yes & No & - & No \\
\hline C 2 & NRA & No & Yes & No & - & - & No \\
\hline C 3 & NRA & No & Yes & Yes & Yes & 2010 & Yes, still not in place \\
\hline C 4 & NRA & - & No & - & - & - & No \\
\hline C 5 & NRA & No & No & - & No & - & - \\
\hline C 6 & NRA & Yes & Yes & No & Yes & 2015 & Yes, audits in place \\
\hline C 7 & NRA & No & No & No & Yes & 2009 & No \\
\hline C 8 & Ministry and NRA & Yes & Yes & Yes & No & 2006 & No \\
\hline C 9 & NRA & Yes & Yes & Yes & Yes & 2008 & Yes, controls in place \\
\hline C 10 & Ministry, NRA and Oper & Yes & Yes & Yes & Yes & 2001 & No \\
\hline C 11 & NRA. & No & No & No & Yes & 2012 & Yes, still not in place \\
\hline C 12 & NRA & Yes & Yes & Yes & Yes & 2001 & Yes, audits in place \\
\hline C 13 & NRA & Yes & Yes & No & No & - & No \\
\hline C 14 & NRA & Yes & Yes & Yes & Yes & 2003 & Yes, controls in place \\
\hline C 15 & NRA & - & - & - & - & - & - \\
\hline C 16 & NRA & No & Yes & Yes & Yes & - & No \\
\hline C 17 & NRA & - & - & - & - & - & - \\
\hline C 18 & Ministry & No & No & No & No & - & No \\
\hline C 19 & TSO and DSO* & Yes & Yes & Yes & Yes & 2001 & Yes, controls in place \\
\hline C 20 & NRA & No & No & - & No & - & No \\
\hline C 21 & NRA & - & - & No & No & - & No \\
\hline C 22 & Ministry delegated NRA & Yes & Yes & Yes & Yes & 2001 & Yes, audits in place \\
\hline C 23 & - & Yes & Yes & No & No & - & No \\
\hline C 24 & NRA & Yes & Yes & Yes & Yes & 2003 & Yes, audits in place \\
\hline C 25 & NRA & Yes & Yes & - & - & - & - \\
\hline C 26 & NRA and DSO/TSO. & Yes & Yes & Yes & Yes & 2011 & Yes, audits in place \\
\hline C 27 & Ministry & Yes & Yes & Yes & Yes & 2010 & Yes, audits in place \\
\hline C 28 & NRA & Yes & Yes & No & Yes & 2016 & Yes, audits in place \\
\hline C 29 & The network operator & No & No & No & No & - & Yes, controls in place \\
\hline C 30 & NRA & No & Yes & No & Yes & 2007 & Yes, audits in place \\
\hline C 31 & - & No & No & Yes & No & - & Yes, audits in place \\
\hline
\end{tabular}

* TSO - Transmission System Operator, DSO - Distribution System Operator 
A characterization of some economic indicators that can influence the continuity of supply performance is also an objective of the benchmarking report that is currently under preparation. For this purpose, is presented in Figure 1 , the average annual investment (CAPEX) in low voltage (LV) and medium voltage (MV) distribution networks for the last five years, in some of the European countries participating in the study.

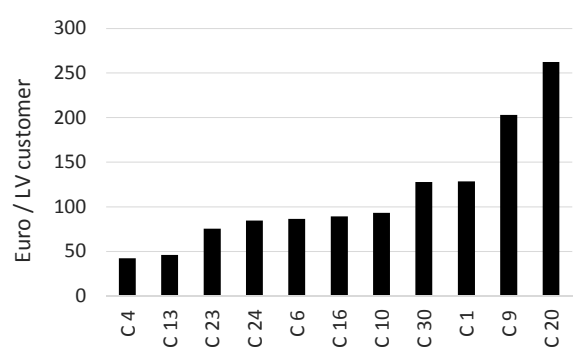

Fig. 1. Annual investment (CAPEX) in LV and MV distribution networks per LV customer (average for 2010-2014).

From the eleven answers collected, it is observed a considerable amplitude in the value of the CAPEX per $\mathrm{LV}$ customer, varying from 42 to 262 euros/customer, with an average of 113 euro/customer.

\section{Technical Characteristics of the Networks}

The technical characteristics of distribution networks can have a considerable influence in their continuity of supply performance. In this sense, benchmarking continuity of supply performance of distribution utilities at a national or international level should also take into account some of those technical characteristics.

One of such technical characteristics of the networks refers to the dispersion of the distribution network throughout the country. In order to characterize this dispersion, as presented in Figure 2, the length of $\mathrm{LV}$ and $\mathrm{MV}$ distribution networks per $100 \mathrm{LV}$ customer is used.

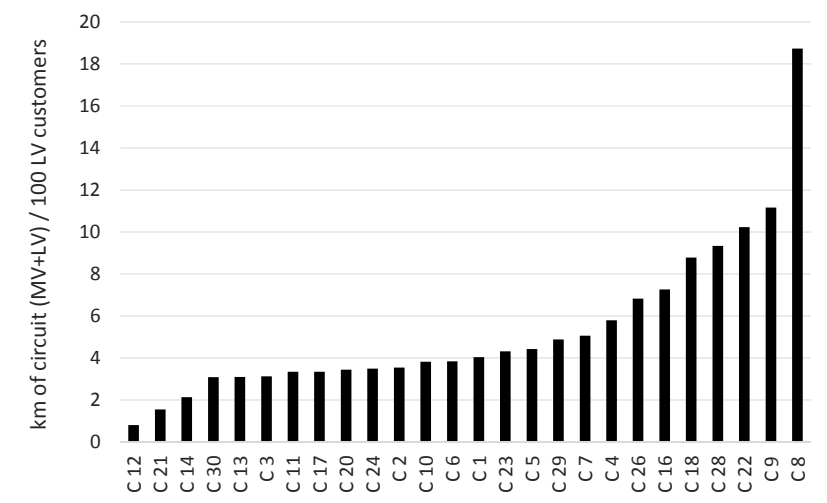

Fig. 2. Length of LV and MV distribution networks per $100 \mathrm{LV}$ customer (average for 2010-2014).

According to the answers, a considerable variation of the distribution network dispersion is observed, varying from 0,8 to $18,7 \mathrm{~km}$ of distribution network/100 LV customer, with a corresponding average of 5,4.
Another technical characteristic that can influence the continuity of supply performance of a network is the percentage of underground cables existing in LV and MV distribution networks. In Figure 3, the percentage of overhead and underground cables existing in LV and MV distribution networks of the European countries is presented.

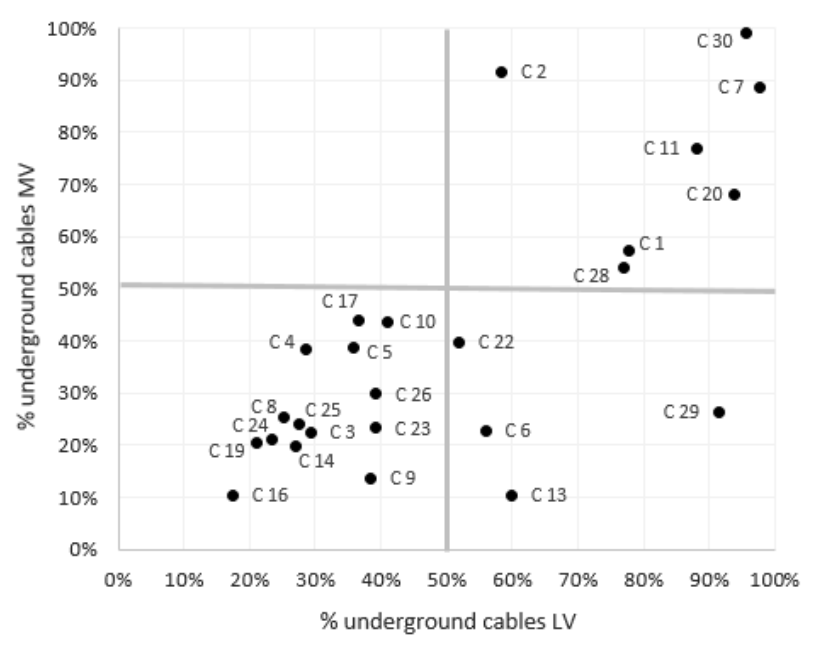

Fig. 3. Percentage of underground cables existing in LV and MV distribution networks (average for 2010-2014).

A clear distinction in the approaches of different countries regarding the percentage of underground cables is identified, with the most countries presenting percentages under $50 \%$, in $\mathrm{LV}$ and $\mathrm{MV}$ networks, and less countries in the cluster above $50 \%$. In comparison with Figure 1, it is also observed that three of the countries in the cluster above $50 \%$ correspond to those with the highest CAPEX per LV customer.

\section{Impact of Techno-economic Context on the Continuity of Supply}

The continuity of supply performance of the different countries are analysed next and some correlations between that performance and the respective technoeconomic context are presented.

Before that, the average duration of all interruptions affecting low voltage customers, per year, also known as SAIDI LV, is presented in Figure 4. The interruptions considered for this performance comparison include all interruptions occurred in upstream voltage levels, with a disaggregation between planned and unplanned interruptions. For the unplanned interruptions, a distinction between exceptional events and other type of causes, is considered

According to the results, very different continuity of supply performances exist from country to country, with the worst performance corresponding to 75 times the best performance. From the analysis of the causes, it is also observed that in some countries, planned interruptions contribute for more than $50 \%$ of the overall interruption duration, while in other countries this contribute is 


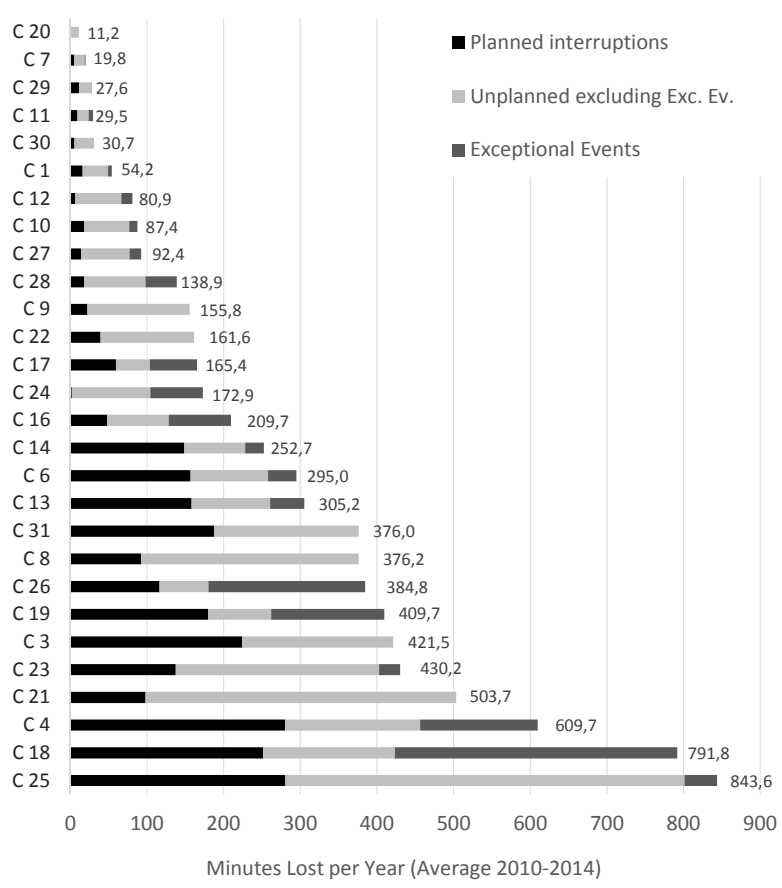

Fig. 4. Duration of overall interruptions (planned and unplanned) affecting LV customers (average for 2010-2014).

residual. For the exceptional events, different behaviours from country to country are also observed.

\section{A. Planned Interruptions}

An interruption is assumed as planned, when the affected customers are notified in advance, allowing them to change their routines and minimize the impact of such interruption in their lives. With the objective of better understanding some of the reasons for the differences observed in the share of planned interruptions, in Table II the rules and approaches used for planned interruptions in each country are presented.

According to the collected data, the share of planned interruptions can vary from $1,1 \%$ to $58,9 \%$ of the overall interruptions duration. Also the rules for notification of customers vary a lot, from countries wherein customers are notified one year before to other countries, where this period corresponds only to 24 hours.

Regarding the main mechanisms identified to prevent the occurrence of planned interruptions in MV and LV distribution networks, they correspond to live works, use of portable generators and reconfiguration of the networks. It is also observed that in most countries with a contribution of the planned interruptions for the overall duration, below 25\%, those three referred mechanisms are used to prevent planned interruptions.

Table II - Different rules and approaches for planned interruptions

\begin{tabular}{|c|c|c|c|c|c|c|c|c|}
\hline \multirow{3}{*}{ Country } & \multirow{3}{*}{$\begin{array}{c}\text { Planned } \\
\text { interruptions in } \\
\text { Total SAIDI }\end{array}$} & \multirow{3}{*}{$\begin{array}{l}\text { Rules for planned interruptions } \\
\text { (notification of customers) }\end{array}$} & \multicolumn{6}{|c|}{ Prevention of planned interruptions } \\
\hline & & & \multicolumn{2}{|c|}{$\begin{array}{l}\text { Live } \\
\text { works }\end{array}$} & \multicolumn{2}{|c|}{$\begin{array}{l}\text { Portable } \\
\text { generators }\end{array}$} & \multicolumn{2}{|c|}{$\begin{array}{l}\text { Network } \\
\text { reconfiguration }\end{array}$} \\
\hline & & & MV & LV & MV & $\mathbf{L V}$ & MV & $\mathbf{L V}$ \\
\hline C 24 & $1,1 \%$ & Mass media at least 36 hours in advance. & $\mathrm{x}$ & & & $\mathrm{x}$ & $\mathrm{x}$ & $\mathrm{x}$ \\
\hline C 12 & $7,8 \%$ & All customers affected: 48 hours before. & & $\mathrm{x}$ & & $\mathrm{x}$ & & $\mathrm{x}$ \\
\hline C 20 & $9,0 \%$ & te & $\mathrm{x}$ & $\mathrm{x}$ & $\mathrm{x}$ & $\mathrm{x}$ & $\mathrm{x}$ & $\mathrm{x}$ \\
\hline C 29 & $13,1 \%$ & No rules. Depend on the network operator. & & $\mathrm{x}$ & & $\mathrm{x}$ & $\mathrm{x}$ & $\mathrm{x}$ \\
\hline C 9 & $14,2 \%$ & - & & $\mathrm{x}$ & & $\mathrm{x}$ & $\mathrm{x}$ & $\mathrm{x}$ \\
\hline C 28 & $15,1 \%$ & - & $\mathrm{x}$ & $\mathrm{x}$ & $\mathrm{x}$ & $\mathrm{x}$ & $\mathrm{x}$ & $\mathrm{x}$ \\
\hline C 31 & $17,3 \%$ & At least 15 days before. & & & $\mathrm{x}$ & $\mathrm{x}$ & $\mathrm{x}$ & \\
\hline C 21 & $19,5 \%$ & At least 3 days before. & & $\mathrm{x}$ & & & $\mathrm{x}$ & \\
\hline C 10 & $20,6 \%$ & TSO plans with customers one year before. & $\mathrm{x}$ & $\mathrm{x}$ & $\mathrm{x}$ & $\mathrm{x}$ & $\mathrm{x}$ & $\mathrm{x}$ \\
\hline C 16 & $22,9 \%$ & At least 48 hours before. & $\mathrm{x}$ & $\mathrm{x}$ & $\mathrm{x}$ & $\mathrm{x}$ & $\mathrm{x}$ & $\mathrm{x}$ \\
\hline C $22 *$ & $24,5 \%$ & All customers affected: 24 hours before. & $\mathrm{x}$ & $\mathrm{x}$ & $\mathrm{x}$ & $\mathrm{x}$ & $\mathrm{x}$ & $\mathrm{x}$ \\
\hline C 8 & $24,6 \%$ & - & & & & & $\mathrm{x}$ & \\
\hline C 7 & $25,0 \%$ & All customers affected: 48 hours before. & & & & & & \\
\hline C 1 & $29,3 \%$ & Grid user has to be informed in advance. & & & $\mathrm{x}$ & $\mathrm{x}$ & $\mathrm{x}$ & \\
\hline C 27 & $30,2 \%$ & Mass media at least 24 hours in advance. & & & & & & \\
\hline C 11 & $31,5 \%$ & - & $\mathrm{x}$ & $\mathrm{x}$ & & & $\mathrm{x}$ & $\mathrm{x}$ \\
\hline C 18 & $31,7 \%$ & - & & & & & & \\
\hline C 23 & $32,0 \%$ & At least 5 days before. & & & & & & \\
\hline C 25 & $33,3 \%$ & At least 15 days before. & & & & & & \\
\hline C 17 & $36,1 \%$ & At least 2 working days before. & & & & & & \\
\hline C 30 & $42,0 \%$ & At least 3 working days before. & & & & & & \\
\hline C 19 & $43,9 \%$ & At least 10 days before. & $\mathrm{x}$ & $\mathrm{x}$ & & & & \\
\hline C 4 & $46,0 \%$ & Mass media at least 24 hours in advance. & & $\mathrm{x}$ & $\mathrm{x}$ & $\mathrm{x}$ & $\mathrm{x}$ & $\mathrm{x}$ \\
\hline C 26 & $50,0 \%$ & Mass media at least 48 hours in advance. & & & $\mathrm{x}$ & $\mathrm{x}$ & $\mathrm{x}$ & $\mathrm{x}$ \\
\hline C 13 & $51,9 \%$ & All customers affected: 48 hours before. & & & & & & \\
\hline C 6 & $53,1 \%$ & TSO: 50 days ahead, DSO: 15 days ahead. & $\mathrm{x}$ & $\mathrm{x}$ & $\mathrm{x}$ & $\mathrm{x}$ & $\mathrm{x}$ & $\mathrm{x}$ \\
\hline C 14 & $58,9 \%$ & Days ahead: 30 (>200kVA), 15 (<200kVA). & & & & & & \\
\hline C 2 & - & Notification one year before (EHV, HV). & & & & & & \\
\hline C 3 & - & Mass media at least 14 days in advance. & & & & & & \\
\hline
\end{tabular}

* There are economic incentives to minimize the consequences of interruption by selecting the most convenient time for interruption for the end-users. With satisfactory notification, the economic consequences are less. 


\section{B. Exceptional Events}

Exceptional events correspond to unpredictable, uncontrollable and severe incidents that affect the transmission and distribution networks. For some countries, it is observed that those kind of events have a significant contribute on the overall interruptions duration (more than $85 \%$ of the total SAIDI). Because of that, and with the objective of better understanding the approaches of the different countries regarding exceptional events, Table III is presented.

It is observed that in most countries a definition of exceptional event exists. However, even in countries not having a definition, the impact of exceptional events on the overall interruptions is reported. In what concerns the responsibility for the classification of an event as exceptional, two different approaches are adopted. A selfregulation procedure for the TSO/DSO and a procedure that includes analysis and approval by the NRA.

Regarding the most frequent causes for exceptional events, they are the result of natural events such as wind, lightning, flood or snow. Because of that, it is expected that as much dispersed are the networks, higher is the expose to the elements and higher is the probability of the network to be affected by an exceptional event. Therefore,

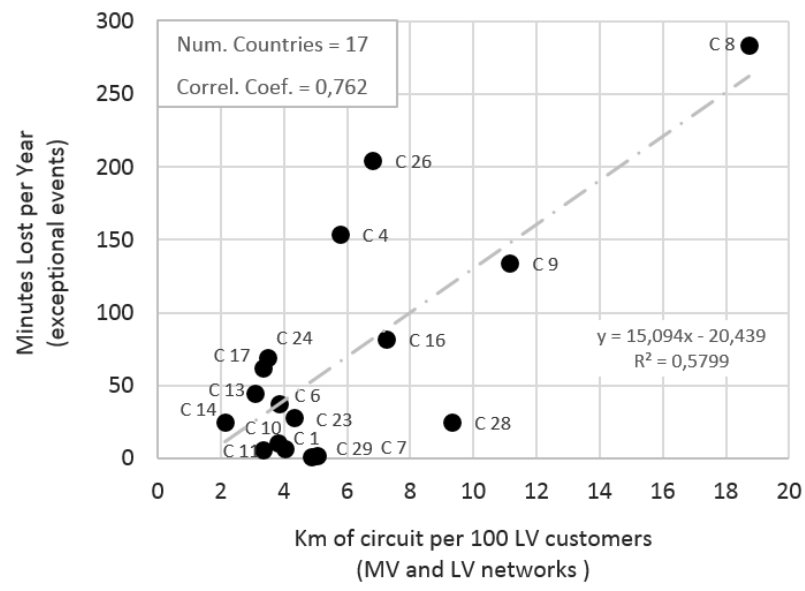

Fig. 5. Correlation between the duration of exceptional events affecting $L V$ customers and the dispersion of the distribution networks (MV and LV).

in order to verify this relationship between the dispersion of the network and duration of interruptions with origin in exceptional events, Figure 5 is presented.

According to the results, it becomes evident that the dispersion of the grid can contribute for its vulnerability to exceptional events.

Table III - Definitions and rules for exceptional events

\begin{tabular}{|c|c|c|c|c|c|c|}
\hline \multirow[t]{2}{*}{ Country } & \multirow{2}{*}{$\begin{array}{l}\text { Exceptional } \\
\text { events in } \\
\text { Total SAIDI }\end{array}$} & \multicolumn{2}{|c|}{$\begin{array}{c}\text { Definition of } \\
\text { exceptional event }\end{array}$} & \multirow{2}{*}{$\begin{array}{l}\text { Responsibility } \\
\text { for } \\
\text { classification }\end{array}$} & \multirow[t]{2}{*}{ Most frequent causes of exceptional events } & \multirow{2}{*}{$\begin{array}{c}\text { Remedies in } \\
\text { TSO/DSO } \\
\text { investment plans? }\end{array}$} \\
\hline & & Yes/No & Where? & & & \\
\hline C 29 & $3,6 \%$ & Yes & Intern. guid. & TSO/DSO & Only natural events during the last 5 years & No \\
\hline C 23 & $6,3 \%$ & Yes & - & - & - & _ \\
\hline C 25 & $6,3 \%$ & Yes & - & - & - & - \\
\hline C 7 & $7,1 \%$ & Yes & Other & NRA & Storm surge, flood and hurricane & - \\
\hline C 14 & $9,8 \%$ & No * & - & - & - & - \\
\hline C 1 & $12,0 \%$ & Yes & Law & NRA & winds $>130 \mathrm{~km} / \mathrm{h}$, flooding, snow and ice storms & No \\
\hline C 10 & $12,1 \%$ & Yes & - & - & - & Yes \\
\hline C 6 & $12,6 \%$ & No & Other & TSO/DSO & Storm, gusty wind, glaze ice, snow & Yes \\
\hline C 13 & $14,6 \%$ & No & - & TSO/DSO & Gener. infeed loss, extreme weather, third party & - \\
\hline C 28 & $17,5 \%$ & No & - & - & - & - \\
\hline C 12 & $17,8 \%$ & Yes & - & NRA & Wind, Rain, Lightning, Snow & - \\
\hline C 11 & $18,4 \%$ & Yes & Other & NRA & Flood and hurricane & - \\
\hline C 31 & $20,3 \%$ & Yes & - & - & - & - \\
\hline C 4 & $25,2 \%$ & Yes & Law & TSO/DSO & Lightning, wind and storm, hail or sleet & Yes \\
\hline C 19 & $36,0 \%$ & No & - & - & - & Yes \\
\hline C 17 & $37,3 \%$ & Yes & Standard & - & - & No \\
\hline C 16 & $38,8 \%$ & Yes $\#$ & - & - & - & Yes \\
\hline C 24 & $39,7 \%$ & Yes & QS Code & NRA & High intensity winds, birds and trees felling & Yes \\
\hline C 26 & $53,1 \%$ & Yes & Other & TSO/DSO & Sleet, extreme wind, storm & - \\
\hline C 18 & $59,6 \%$ & No & - & TSO/DSO & Weather conditions (wind, ice) & No \\
\hline C 27 & $66,8 \%$ & Yes & - & - & - & No \\
\hline C 8 & $75,4 \%$ & Yes & - & - & - & No \\
\hline C 9 & $85,8 \%$ & No & - & - & - & Yes \\
\hline C 2 & - & Yes & Law & - & EHV/HV: extreme weather conditions & Yes \\
\hline C 3 & - & Yes & - & - & - & - \\
\hline C 5 & - & Yes & - & - & - & - \\
\hline C 20 & - & No & - & - & - & - \\
\hline C 21 & - & No & - & - & - & - \\
\hline C 22 & - & No & Other & Other & Thunderstorms, wind/vegetation, snow/ice & No \\
\hline C 30 & - & Yes & Intern. guid. & TSO/DSO & - & No \\
\hline
\end{tabular}

* There is no definition of exceptional events, but in guaranteed standards there is a definition of 'extreme weather', if the number of MV interruptions caused by a weather even reaches or exceeds a value predefined for the different DSO. In overall standards there is a definition of 'other event', which includes system collapse, terror attacks and other events.

\# There is a definition of 'storm days', but no other exceptional events are defined. 


\section{Underground Cables}

While the dispersion of the network increase its exposure to the elements and contribute for a worst performance in what concerns continuity of supply, it is expected that the use of underground cables could have an inverse impact, increasing the resilience of the network.

In this sense, in order to analyse the impact of such technical characteristic in the continuity of supply, the correlation between the overall duration of interruptions (planned and unplanned, including exceptional events) and the percentage of underground cables in MV and LV are presented in Figure 6 and Figure 7, respectively.

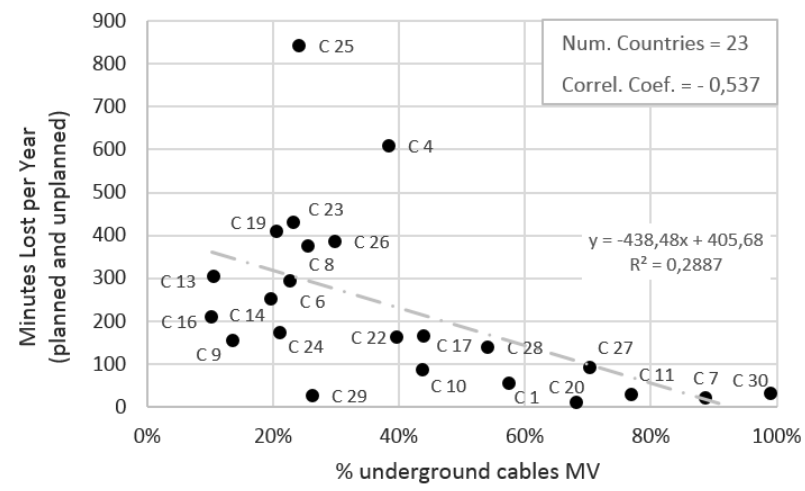

Fig. 6. Correlation between the duration of overall interruptions affecting LV customers and the percentage underground cables in MV.

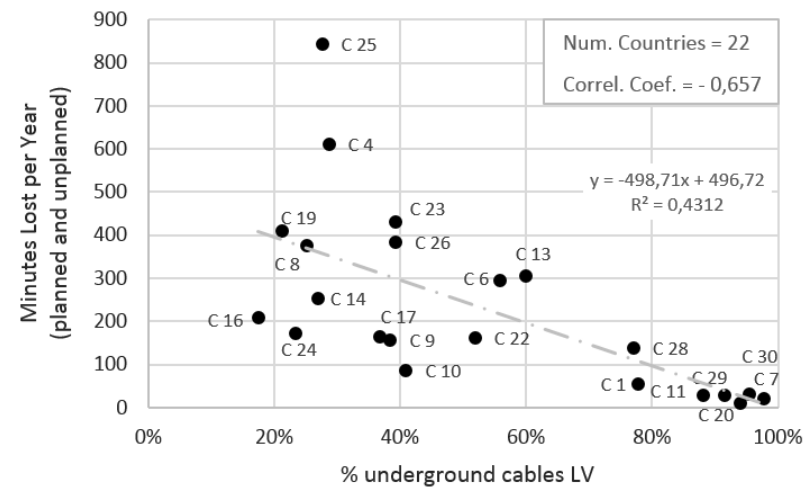

Fig. 7. Correlation between the duration of overall interruptions affecting LV customers and the percentage underground cables in LV.

According to the results, it is observed a negative correlation between the percentage of underground cables and the interruption duration. This means that as much underground cables are used, as lower is the overall duration of interruptions. It is also observed that the correlation is stronger in LV than in MV. This can be justified by the fact that, in most countries, the total length of LV circuits being larger than the length of MV circuits.

\section{Annual Investment in Distribution}

Since the option for underground cables usually corresponds to additional investment in the networks, in Figure 8, is analysed the correlation between CAPEX

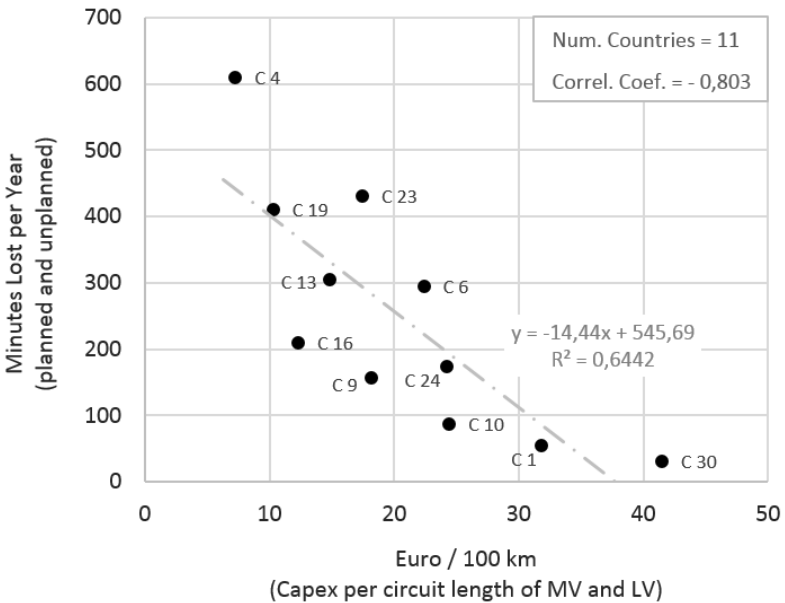

Fig. 8. Correlation between the annual investment in distribution network (MV and LV) and the duration of overall interruptions affecting LV customers.

in distribution networks (MV and LV) and the overall duration of interruptions. For the eleven countries with available data, the results demonstrate a significant correlation between the CAPEX of distribution network and the continuity of supply performance.

\section{Conclusions}

In this paper, it is presented a comparison of the continuity of supply performance of the distribution networks from 31 European countries. This comparison takes into account the technical characteristics of the networks and the respective economic regulatory context, with the objective of identifying correlations and isolating some of the characteristics that can influence that continuity of supply performance.

The analysis of the overall duration of interruptions demonstrated the existence of very different performances in each country. Also the contribution of planned interruptions and exceptional events presented considerable different behaviours from country to country.

The study also demonstrated that most countries with lower share of planned interruptions in the overall duration of interruption, make use of live works, portable generators and reconfiguration of networks to prevent such interruptions.

During the study, it was concluded that the use of underground cables considerably increase the resilience of the network and improve the continuity of supply. This kind of improvement would be only possible with additional investment in the networks. It was also demonstrated that more dispersed networks present lower continuity of supply performance, because they enhance the occurrence of exceptional events.

For future developments, since it is expected that higher levels of networks automation can improve the levels of the continuity of supply [11], the topic will be addressed. 


\section{Disclaimer}

The text in this paper represents the personal opinion of the authors and not necessarily the opinion of the Portuguese regulatory authority for energy services (ERSE).

\section{References}

[1] J. Román, J. Gómez, A. Muñoz, and J. Peco, "Regulation of distribution network business," IEEE Trans. Power Delivery, vol. 14, pp. 662-669, Apr. 1999.

[2] V. Ajodhia, and R. Hakvoort, "Economic regulation of quality in electricity distribution networks," Utilities Policy, vol. 13, pp. 211-221, Sep. 2005.

[3] D. Giannakis, T. Jamasb, and M. Pollitt, "Benchmarking and incentive regulation of quality of service: an application to the UK electricity distribution networks," Energy Policy, vol. 33, pp. 2256-2271, Nov. 2005.

[4] V. Ajodhia, L. Schiavo, and R. Malaman, "Quality regulation of electricity distribution in Italy: an evaluation study," Energy Policy, vol. 34, pp. 1478-1486, Sep. 2006.

[5] E. Fumagalli, P. Garrone, and L. Grilli, "Service quality in the electricity industry: the role of privatization and managerial behavior," Energy Policy, vol. 35, pp. 62126224, Dec. 2007.
[6] A. Ter-Martirosyan and J. Kwoka, "Incentive regulation, service quality, and standards in U.S. electricity distribution," Journal of Regulatory Economics, vol. 38, pp. 258-273, Dec. 2010.

[7] E. Fumagalli, L. Lo Schiavo, and F. Delestre, Service Quality Regulation in Electricity Distribution and Retail, Berlin: Springer, 2007.

[8] M. Schmidthaler, J. Cohen, J. Reichl and S. Schmidinger, "The effects of network regulation on electricity supply security: a European analysis," Journal of Regulatory Economics, vol. 48, pp. 285-316, Dec. 2015.

[9] A. Cullmann, "Benchmarking and firm heterogeneity: a latent class analysis for German electricity distribution companies," Empirical Economics, vol. 42, pp. 147-169, Feb. 2012.

[10] CEER - Council of European Energy Regulators, About the European Energy Regulators [Online]. Available: http://www.ceer.eu/portal/page/portal/EER_HOME/EER_A BOUT.

[11] A. Rodriguez, P. Frías, J. Reneses, R. Cossent and C. Mateo, "Optimal investment in smart MV/LV substations to improve continuity of supply," International Journal of Electrical Power \& Energy Systems, vol. 62, pp. 410-418, Nov. 2014. 